\title{
Palliative treatment of life-threatening hemoptysis with silicone stent insertion in advanced lung cancer
}

\author{
Emanuela Barisione1, Carlo Genova2, Marco Grosso', Mercedes Pasquali1, \\ Alessandro Blanco', Raffaella Felletti', Mario Salio1 \\ 1 Pulmonology Unit, IRCCS San Martino - IST Hospital, Genoa \\ 2 Medical Oncology Unit, IRCCS San Martino - IST Hospital, Genoa, Italy
}

\begin{abstract}
Massive hemoptysis is a stressful and life-threatening event that can occur in lung cancer patients. The management of this event is usually challenging, and can involve surgery, embolization, and bronchoscopy. Unfortunately, while surgery can offer a definitive solution to hemoptysis, lung cancer patients are often excluded from this approach. On the other hand, bronchial arterial embolization rarely results in long-term control of bleeding.

Endoscopy allows a skilled physician to perform mechanical tamponade or laser photocoagulation of bleeding lesions and preserve the main airways. While endoscopic stent placement is usually performed in order to treat stenosis, it has been occasionally employed to isolate and mechanically block the bleeding sites within the bronchial tree.

We present the cases of two patients suffering from lung cancerrelated life-threatening hemoptysis; both patients were successfully treated by positioning a silicone stent during emergency bronchoscopy. Subsequently, we present a concise review of the available literature.
\end{abstract}

Corresponding author: Emanuela Barisione, IRCCS San Martino IST, Largo Rosanna Benzi 10, 16132 Genova, Italy.

Tel. +39.010 .5555790 - Fax +39.010 .5556372 .

E-mail: emanuela.barisione@hsanmartino.it

Key words: Lung cancer; massive hemoptysis; silicone stent; rigid bronchoscopy; laser photocoagulation.

Conflict of interest: the authors declare no conflict of interest or financial disclosure regarding the publication of this paper.

Received for publication: 23 October 2016

Accepted for publication: 31 January 2017

(C) Copyright E. Barisione et al., 2017

Tipografia PI-ME Editrice, Italy

Monaldi Archives for Chest Disease 2017; 87:781

doi: 10.4081/monaldi.2017.781

This article is distributed under the terms of the Creative Commons Attribution Noncommercial License (by-nc 4.0) which permits any noncommercial use, distribution, and reproduction in any medium, provided the original author(s) and source are credited.

\section{Introduction}

Hemoptysis is an alarming and sometimes dangerous event occurring in $19-32 \%$ of lung cancer patients. The reported mortality rate for mild and moderate hemoptysis is $2.5 \%$ and $6 \%$, respectively, while massive events, albeit uncommon (5-15\%) are lethal in 38\% of cases; notably, the mortality rate of hemoptysis related to lung cancer is higher compared to other causes [1].

The treatment options for this event include pharmacologic measures such as antifibrinolytic agents, vascular embolization, endoscopic procedures, and surgical resection. In particular, endoscopy has a relevant role in the emergency management of massive hemoptysis, as an urgent rigid bronchoscopy or a flexible bronchoscopy inside a tracheal tube is efficient in clearing the airways, tamponing the bleeding and therefore preserving ventilation, provided that the procedure is performed by skilled personnel; however, the long-term efficacy of the known endoscopic procedures is reportedly limited $[2,3]$.

Here we describe two cases of patients with massive hemoptysis who underwent endoscopic treatment with the aim of stopping bleeding permanently.

\section{Case Report}

\section{Case 1}

The first case report involves a 51-year-old woman affected by adenocarcinoma of the lung; no relevant bleeding diathesis or anticoagulant/antiaggregant treatment was reported. The patient had a large neoplastic lesion involving the upper right lobe, as well as multiple small lesions in both lungs, mediastinal lymphoadenopathies, and right pleural effusion (stage IV). The patient was a former smoker (30 packs/years). The research for actionable mutations of the epidermal growth factor receptor (EGFR) gene or translocations of the anaplastic lymphoma kinase (ALK) gene was negative, thus the patient received a chemotherapy combination of cisplatin plus pemetrexed for 4 cycles; the treatment was substantially well tolerated, and no significant reduction in platelet count was reported. Notably, the patient reported episodes of mild hemoptysis since the time of the diagnosis.

Six months after the diagnosis, the patient was referred to the emergency department of the San Martino Hospital - National Institute for Cancer Research for an episode of moderate hemoptysis, where a computed tomography (CT)-scan showed increase of the tumor mass in the right upper lobe with involvement of the right upper lobe bronchus with occlusion of its ostium; the invading neoplastic tissue was treated with endoscopic laser photocoagulation (diode laser), resulting in marked reduction of the bleeding. 
However, three weeks later, the patient was hospitalized for a new hemoptysis episode; while the episode was initially described as massive, when the patient was referred to our pulmonology unit, the bleeding was significantly reduced and did not require emergency treatment; therefore, other therapeutic options were considered. A surgical palliative procedure was excluded because the neoplasm involved the thoracic great vessels and the right tracheobronchial angle; hence, a transcatheter embolization was performed by the staff of the interventional radiology unit, leading to significant reduction of bleeding.

One week later, while the patient was still hospitalized in the pulmonology unit after the radiologic procedure, she suffered from an episode of massive hemoptysis, which led to acute respiratory failure. The patient immediately underwent an emergency intubation with a rigid bronchoscope; during the procedure, mechanical tamponade and a diode laser photocoagulation of the bleeding source were performed while the airways were kept patent, thus preserving ventilation. In order to prevent further episodes of hemoptysis, a silicone stent $13 \times 30$ mm was inserted in the right main bronchus, occluding the entrance of the right upper lobe bronchus (Figure 1). The procedure was effective, as no further bleeding episodes were observed. Two months later, the patient died due to disease progression.

\section{Case 2}

The second case involves a 78-year-old male former smoker (40 pack/years) affected by a squamous cell carcinoma in the lower lobe of the right lung; no relevant bleeding diathesis or anticoagulant/antiaggregant treatment was reported. Due to the size of the tumor, the patient was excluded from curative surgery and therefore considered eligible for chemotherapy followed by thoracic radiation therapy. The patient received 2 cycles of carboplatin plus etoposide from August 2015 to September 2015, followed by a CT-scan showing progressive disease in the right lung; for this reason, the planned radiation therapy was omitted and the patient received second-line treatment with Nivolumab.

Since February 2016, the patient had been suffering from episodic blood-tinged sputum; in June 2016, a progressive worsening of the bleeding was observed, until he had to be taken to the emergency room for an episode of massive hemoptysis. During bronchoscopy, an evident intra-bronchial disease progression was observed, with bleeding neoplastic tissue reaching the entrance of the intermediate bronchus. A diode laser photocoagulation therapy was performed using a flexible bronchoscope, but it did not prove sufficiently effec-

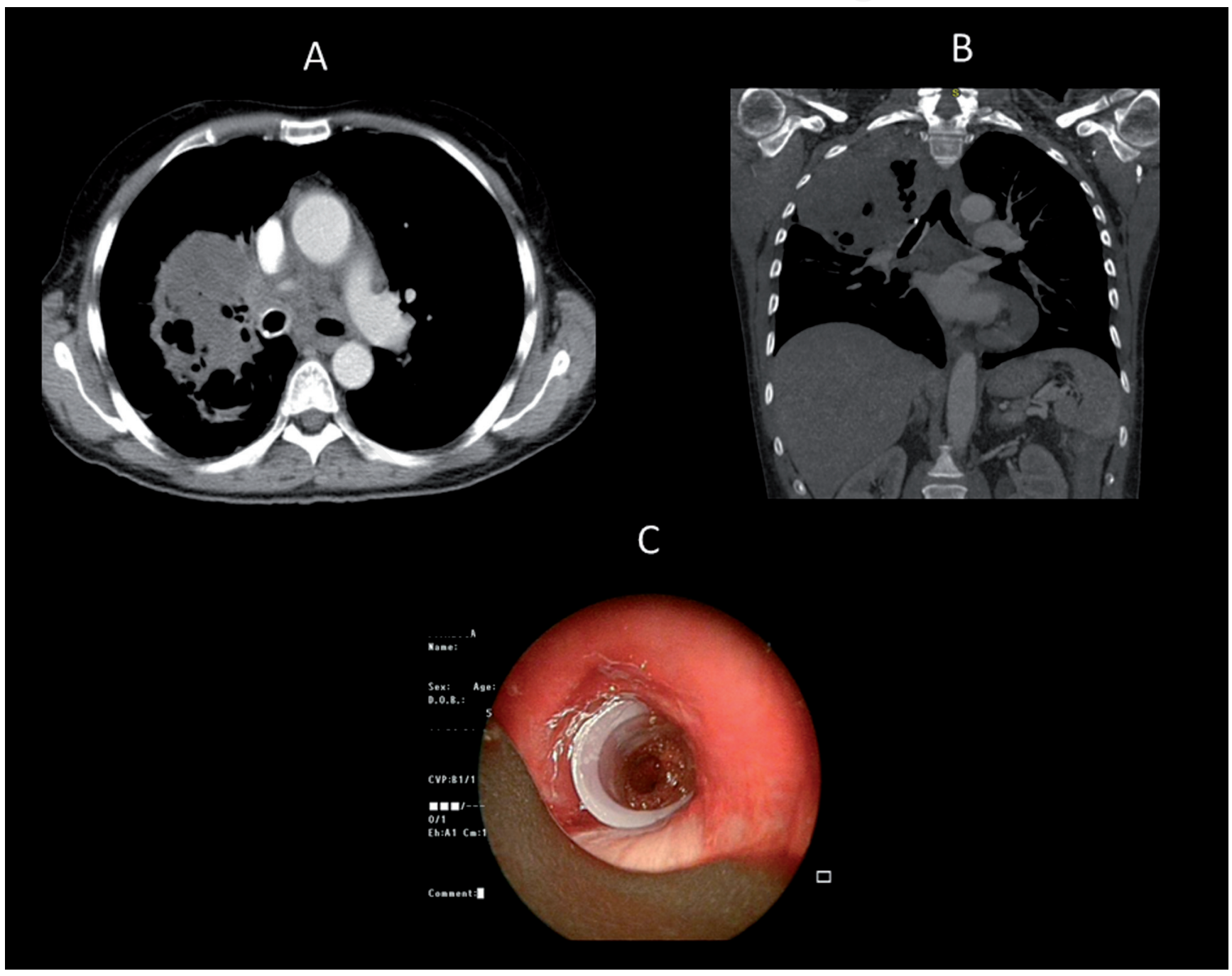

Figure 1. Relevant images of the Case Report 1. A) Coronal and B) sagittal CT scans after insertion of the silicone stent. C) Dumon stent placed in the right main bronchus. 
tive in stopping the bleeding. On the basis of the experience that had been developed in the previous case, the decision of inserting a stent in order to stop the hemorrhage was taken. However, at that time a suitable closed distal stent was not readily available in the pulmonology unit; hence, a $13 \times 25 \mathrm{~mm}$ silicone stent was closed in its distal part with a suture thread and subsequently positioned in the intermediate bronchus to apply a mechanical tamponade (Figure 2). The procedure was immediately effective and no more hemoptysis episodes were reported; after the hospitalization, the patient resumed its planned anti-neoplastic treatment and he is currently receiving Nivolumab.

\section{Discussion}

Hemoptysis is a common symptom in lung cancer and is the terminal event in $3 \%$ of the cases. Hemoptysis often increases with the progression of the disease and in particular in the endoscopic progression. The presence of hemoptysis greatly impacts the quality of life of lung cancer patients; even episodes of mild or moderate hemoptysis are often perceived as stressful events and imply the possibility of a massive bleeding, which is always a dangerous and frightening occurrence for the patients and requires prompt medical intervention. To date there is no clear consensus on the definition of massive hemoptysis. Currently, rather than using a quantitative definition, it is preferred to define massive hemoptysis based on its clinical consequences, such as respiratory failure and hemodynamic instability [4].

Massive hemoptysis in patients with advanced thoracic malignancies can be difficult to manage, due to the global conditions of the patients and cancer-related comorbidities; in such cases, bleeding can be caused by necrosis of a tumor, rupture of small blood vessels in the area, or tumor invading one of the pulmonary blood vessels [5]. In such cases, the first step is to define the site of hemorrhage, as this information is critical for the subsequent steps; a CT scan can locate the site of bleeding in $70-88 \%$ of cases [6]. As one might expect, respiratory and hemodynamic conditions affect the patient's course and need to be promptly managed. If marked bleeding causes acute respiratory failure, an endoscopic procedure with rigid bronchoscope performed by skilled personnel is required, as it allows the physician to remove blood and clots, use blocking devices as the balloon, and to perform mechanical tamponade, thus preserving ventilation. In the current clinical practice, however, not all bronchoscopists are able to use a rigid bronchoscope;

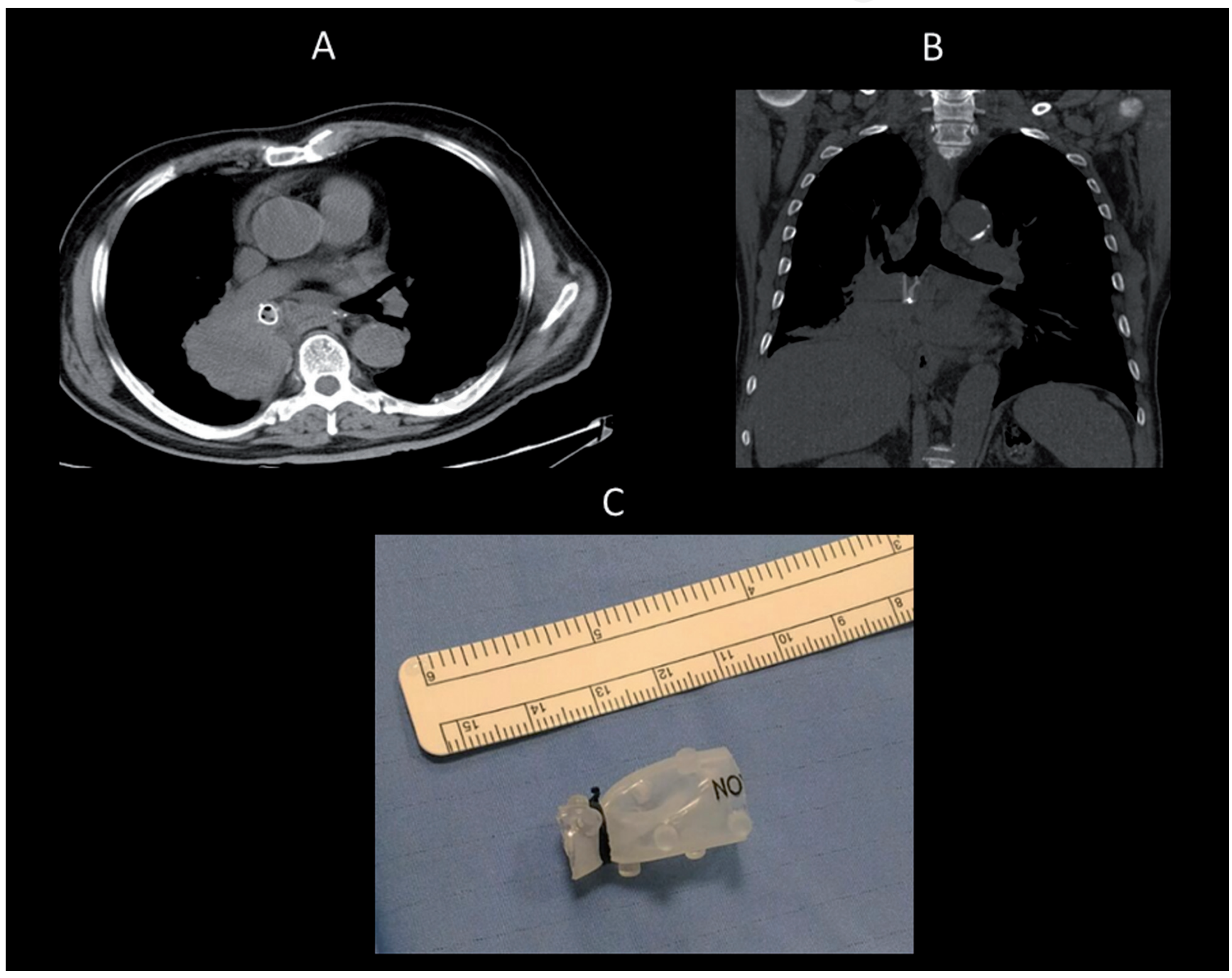

Figure 2. Relevant images of the Case Report 2. A) Coronal and B) sagittal CT scans after insertion of the silicone stent. C) Modified Dumon stent before endoscopic placement. 
by consequence, during a massive hemoptysis it is necessary to intubate the patient with an endotracheal tube using a flexible bronchoscope. In most cases, endobronchial tamponade offers only temporary relief and does not result in long-term benefit [7]. Bronchial artery embolization (BAE) is a therapeutic modality for life-threatening massive hemoptysis. This modality has revolutionized management of these events, being a less invasive but reliable procedure that leads to excellent short-term therapeutic outcomes (immediate decrease or resolution of bleeding in most cases) [8]. If needed, BAE can be repeated multiple times; however, bleeding relapse is very frequent in cancer patients, whose prognosis remains poor [9]. Another possible option for severe hemoptysis is surgery; this procedure is often resolutive, as it is meant to remove the bleeding cause, but its applicability in the case of lung cancer patients is extremely limited due to technical difficulties and the general conditions of oncologic patients.

In 2010, Sakr and Dutau published an update on the role on the bronchoscopic management of massive hemoptysis [3]. In this publication, they proposed a management algorithm in which the choice between BAE and surgery is the last step after more conservative approaches [3]. However, in a significant number of cases, BAE was ineffective and surgery was not feasible; therefore, other therapeutic options are highly advised in this setting. During bronchoscopy, bronchial stents are normally intended to recanalize the airway in case of neoplastic obstruction and only few published cases involve their use with the aim of tamponing a neoplastic hemorrhage. In the two reported cases, tamponade with a silicone stent in two different sites, led to the definitive cessation of bleeding; in the second case, the modified silicone stent was effective and even allowed the patient to resume his systemic anti-neoplastic treatments.

In order to identify the available literature, we performed a PubMed research using the following parameters: ('endobronchial stent' OR 'airway stent') AND ('hemoptysis' OR 'bleeding' OR 'hemorrhage'); 20 publications were found, only 3 of them actually related to the subject.
An additional research using 'hemoptysis' and 'silicone stent' showed a single publication [10]. The global number of published cases is reported in Table 1. The total number of reported patients, including our cases, is 8 . The median age at the time of the procedure was 62 years (range: 46-78), and the male/female ratio is 6:2; all the reported cases were affected by non-small cell lung cancer, but the exact histology was defined only in 4 cases ( 1 adenocarcinoma and 3 squamous cell carcinomas). Only 3 out of 8 patients had received other treatments for hemoptysis before undergoing stent placement. The median time from diagnosis of lung cancer to treatment with stents was 12 months (range: 5-17 months), excluding a case where the bleeding was iatrogenic (following a bronchial biopsy). In 5 cases, a covered nitinol stent was employed, while in another case a Y-silicone stent was placed on a secondary carina and straight silicone stents were placed in the two cases managed within our institution. In six cases, the stent placement resulted in bleeding cessation; in one case, the bleeding was only briefly reduced and, ultimately, the treatment was not considered effective. The median survival after stent insertion was 90 days (range: 2-120 days). In six patients, hemoptysis was not the cause of death, and one patient is currently alive $[5,10-12]$.

\section{Conclusions}

In our opinion, based on the experience developed within our institution and on the available publications, endobronchial stent placement, whether made of metal or silicone, should be considered a suitable and potentially resolution option for the management of moderate/severe and recurrent hemoptysis. While both metal and silicone stents have been used for this purpose, our experience suggests that silicone stents are more manageable, as they can be promptly and successfully adapted to the bleeding site in the tracheobronchial tree (as reported in our second case).

Table 1. Patient and treatment characteristics.

\begin{tabular}{|c|c|c|c|c|c|c|c|c|c|}
\hline $\begin{array}{l}\text { Author } \\
\text { Year }\end{array}$ & $\begin{array}{l}\text { Gender } \\
\text { Age }\end{array}$ & Histology & $\begin{array}{l}\text { Previous } \\
\text { hemoptysis } \\
\text { treatment }\end{array}$ & $\begin{array}{l}\text { Time from } \\
\text { diagnosis } \\
\text { (months) }\end{array}$ & $\begin{array}{l}\text { Tumor } \\
\text { site }\end{array}$ & $\begin{array}{l}\text { Stent } \\
(\mathrm{mm})\end{array}$ & $\begin{array}{l}\text { Stent } \\
\text { site }\end{array}$ & $\begin{array}{c}\text { Stop } \\
\text { bleeding }\end{array}$ & $\begin{array}{l}\text { Survival } \\
\text { (days) }\end{array}$ \\
\hline Brandes 2008 [11] & F 72 & NSCLC & - & 17 & LLL & $\begin{array}{c}\text { Poliflex 8x20 } \\
\text { CN stent } \\
14 \times 60\end{array}$ & $\begin{array}{c}\text { LLL } \\
\text { LMB-LUL }\end{array}$ & Yes & 120 \\
\hline Chung 2010 [12] & M 49 & SCC & - & 5 & LMB & CN stent & LMB & Partial & 90 \\
\hline Lee 2011 [5] & M 78 & NSCLC & RT & 12 & RUL & $\begin{array}{l}\text { CN stent } \\
12 \times 43 \\
\text { CN stent } \\
12 \times 53\end{array}$ & $\begin{array}{l}\text { RLL-RMB } \\
\text { RMB }\end{array}$ & No & 2 \\
\hline Lee 2011 [5] & M 72 & SCC & - & 20 & LMB & $\begin{array}{c}\text { CN stent } \\
12 \times 53\end{array}$ & LMB & Yes & 16 \\
\hline Lee 2011 [5] & M 46 & NSCLC & - & 30 & LMB & $\begin{array}{l}\text { CN stent } \\
18 \times 40 \\
\text { CN stent } \\
120 \times 30\end{array}$ & $\begin{array}{l}\text { Trachea } \\
\text { RMB }\end{array}$ & Yes & 90 \\
\hline Dalar 2014[10] & M 52 & NSCLC & - & Iatrogenic & LUL & $\begin{array}{l}\text { Y silicon stent } \\
14 \times 10 \times 10\end{array}$ & LMB-LLL-LUL & Yes & 90 \\
\hline This study 2016 & F 51 & $\mathrm{ADC}$ & $\begin{array}{c}\text { RT - } \\
\text { Laser-BAE }\end{array}$ & 6 & RUL & $\begin{array}{c}\text { S stent } \\
13 \times 30\end{array}$ & IB-RMB & Yes & 60 \\
\hline This study 2016 & M 78 & SCC & Laser & 12 & RLL & $\begin{array}{c}\text { S stent } \\
13 \times 25\end{array}$ & IB & Yes & AWD (70) \\
\hline
\end{tabular}

F: female; M: male; NSCLC: non-small cell lung cancer; SCC: squamous cell carcinoma; ADC: adenocarcinoma; RT: radiotherapy; LLL: left lower lobe; LMB: left main bronchus; RUL: right upper lobe; LUL: left upper lobe; CN stent: covered nitinol stent; S Stent: silicon stent; RLL: right lower lobe; RMB: right main bronchus; IB: intermediate bronchus; AWD: alive with disease. 


\section{References}

1. Hirshberg B, Niran I, Glazer M. Hemoptysis: etiology, evaluation, and outcome in a tertiary referral hospital. Chest 1997;112:440-4.

2. Milani GF, Simonassi C, Salio M. Palliative therapy. Monaldi Arch Chest Dis 2011;75:72-7.

3. Sakr L, Dutau H. Massive hemoptysis: an update on the role of bronchoscopy in diagnosis and managemen. Respiration 2010;80: 38-58.

4. Kvale PA, Selecky PA, Prakash UB. American College of Chest Physician. Palliative care in lung cancer: ACCP evidence-based clinical practice guidelines (2nd edition). Chest 2007;132: S368-403.

5. Lee SA, Kim DH, Jeon GS. Covered bronchial stent insertion to manage airway obstruction with hemoptysis caused by lung cancer. Korean J Radiol 2012;13:515-20.

6. Khalil A, Soussan M, Mangiapan CG, et al. Utility of high resolution chest CT scan in the emergency management of hemoptysis in the intensive care unit: severity, localization and aetiology. Br J Radiol 2007;80:21-5.

7. Dweik RA, Stoller JK. Role of bronchoscopy in massive hemoptysis. Clin Chest Med 1999;20:89-105.

8. Hayakawa K, Tanaka F, Torizuka T, et al. Bronchial artery embolization for hemoptysis: immediate and long term results. Cardiovasc Interv Radiol 1992;15:154-9.

9. Wang GR, Ensor JE, Gupta S, et al. Bronchial artery embolization for the management of hemoptasis in oncology patients: utility and prognostic factors. J Vasc Interv Radiol 2009;20:722-9.

10. Dalar L, Ozdemir C, Sokucu S, et al. The management of near-fatal hemoptysis with left secondary carinal Y stent. Case Reports in Pulmonolgy 2014; 2014:709369.

11. Brandes C, Schmidt E, Yung R. Endobronchial stent placement as a novel management approach to massive hemoptysis from lung cancer. J Thorac Oncol 2008;3:1071-2.

12. Chung H, Park M, Kim DH, et al. Endobronchial stent insertion to manage hemoptysis cause by cancer. J Korean Med Sci 2010;25: 1253-5. 